Artículos

\title{
Música PARA Las DIVINIDADES DE LA LLUVIA. ReCONSTRUCCIÓN de los ritos mayas del período Clásico Tardío en la Grieta Principal de Aguateca, El Petén, Guatemala
}

\author{
Reiko Ishihara
}

\begin{abstract}
Resumen: Investigaciones arqueológicas en la Grieta Principal de Aguateca, El Petén, Guatemala, una grieta profunda que corre en medio de este sitio maya del período Clásico Tardío, evidencian una variedad de actividades rituales. Este artículo se enfoca en una parte específica de la grieta, donde la presencia de fenómenos naturales, la topografía del área, y gran cantidad de fragmentos de instrumentos musicales indican la posible realización de ceremonias de la lluvia en forma regular. Asimismo, el conjunto de artefactos y su contexto sugieren que las prácticas pudieron coincidir con eventos políticos importantes y que las clases dominantes tomaron parte en estos rituales.
\end{abstract}

Palabras clave: cuevas, grieta, ritos, ceremonias, mayas, Aguateca, lluvia, música, instrumentos musicales, Guatemala.

Enviado a dictamen: 16 de febrero de 2009

Aprobación: 27 de abril de 2009

Revisiones: 1

Reiko Ishihara, doctora en Antropología por la Universidad de California en Riverside, EEUU, asociada del Post-Doctorado en Estudios Mayas, Programa Pre-Colombino del Centro de Investigaciones, Colección y Biblioteca Dumbarton Oaks de la Universidad de Harvard en Washington D.C. Temas de especialización: arqueología de cuevas en Mesoamérica, iconografía maya, antropología de la educación, arqueología pública. Correo electrónico: reikoish@gmail.com.
Abstract: Archaeological investigations in the Main Chasm, a deep chasm that runs through the Late Classic Maya site of Aguateca, Peten, Guatemala, revealed evidence of a variety of ritual practices. This paper focuses on one area of the chasm, where a combination of natural phenomena, topography of the locale, and high frequency of musical instrument fragments indicate that rain ceremonies comprised a primary practice. The associated artifact assemblage and context also suggest that the activities may temporally correlate with a major political event and socially imply that upper class peoplewere involved in the ritual performances.

Keywords: caves, chasm, rites, maya, Aguateca, rain, music, Guatemala.

\section{Introducción}

$\mathrm{D}$ ebido a que de la agricultura dependía la vida de la población en la época prehispánica, las lluvias, tanto en cantidad como en tiempo, constituían una preocupación central para los mayas de ese tiempo. De acuerdo con estudios etnográficos y etnohistóricos, las ceremonias para pedir lluvia eran uno de los ritos más importantes de las comunidades durante el ciclo agrícola, lo que sugiere el interés en este tema ya existía por lo menos a la llegada de los españoles 
(Gann 1968; López, 1612; Scholes y Adams, 1938). A su vez, la combinación de estudios arqueológicos con investigaciones iconográficas demuestra la significancia de temas relacionados con el agua y la lluvia durante la época prehispánica, no sólo en la cultura maya sino también en las tradiciones de varios grupos mesoamericanos (Brady y Ashmore, 1999; Ishihara, et al. 2006; Lucero y Fash, 2006; Scarborough, 2003). Asimismo, estudios relativamente recientes sugieren la posibilidad de que ceremonias dirigidas a la petición de lluvia pudieron ser realizadas en cuevas durante el período clásico (Andrews, 1970; Morehart, 2002; Moyes, 2006; Rissolo, 2005). Sin embargo, la evaluación de actividades relacionadas con ceremonias de la lluvia en cuevas es vaga, ya que se basan principalmente en asociaciones generales entre cuevas y agua.

En este artículo se identifican posibles correlatos arqueológicos y otros factores relevantes que permiten sugerir que ceremonias de la lluvia fueron realizadas en el Cerro Frío (Operación 31D) dentro de la Grieta Principal de Aguateca, El Petén, Guatemala, una ciudad del período clásico tardío (ca. d.C. 600-900). En la primera sección se describe el sitio arqueológico y la importancia de la grieta en la topografía del paisaje de Aguateca. En las siguientes secciones se describe el Cerro Frío, el fenómeno natural observado dentro de la grieta y el conjunto arqueológico del área. De esta forma, todos los factores apuntan a sugerir que ceremonias realizadas en el Cerro Frío posiblemente se centraron en las lluvias. Por último, se discuten las implicaciones sociales y políticas de las ceremonias de la lluvia que pudieron haberse realizadas en la grieta, en el contexto de los eventos políticos que sucedían en ese momento.

\section{Investigaciones en la Grieta Principal de Aguateca}

El sitio arqueológico de Aguateca, El Petén, Guatemala, conocida por su breve historia y rápido abandono, se estableció alrededor del año 700 d.C. como la capital gemela de Dos Pilas, una de las entidades políticas más poderosas de la región de Petexbatún durante el período clásico tardío (Figura l). La ciudad se caracteriza por la presencia de una grieta que corre en medio del sitio. La grieta es un rasgo natural que mide aproximadamente 860 metros de largo, 10 a 70 metros de profundidad y 1.5 a 15 metros de ancho (Figuras 2 y 3 ) y en este artículo se le denomina Grieta Principal. En ambos lados de la Grieta Principal fueron construidas estructuras que forman la parte central de la comunidad. La mayoría de las estructuras residenciales y administrativas están ubicadas en la parte norte del sitio, rodeadas por una escarpa empinada al este y la Grieta Principal al oeste. Aguateca, como capital, fue establecida durante una época cuando la situación política de la región era turbulenta, por lo que la ubicación de la ciudad fue seleccionada, en parte, por la presencia de la escarpa y la grieta que sirvieron como barreras naturales protectoras (Inomata, 1997:337). No obstante, a pesar de contar con la topografía como defensa natural y un sistema de muros defensivos que fueron construidos en la parte central, Aguateca fue asaltada cerca del 810 d.C., y muchos edificios, de la parte supuestamente protegida, fueron quemados, teniendo como resultado el rápido abandono de la ciudad (Inomata, 1997).

Como parte de investigaciones recientes del Proyecto Arqueológico Aguateca (Ponciano, et al. 2004, 2005), la Grieta Principal fue estudiada con el propósito de examinar su importancia religiosa y política en relación con la historia del asentamiento en Aguateca. El significado de la grieta se observa en el glifo toponímico, leído K'inich Pa' Witz (Stephen Houston, comunicación personal, 2004), el cual muestra gráficamente un cerro partido, una representación de la grieta en la cima de la escarpa (Stuart y Houston, 1994: 10, fig. 8) Como un rasgo subterráneo, la grieta cabe dentro de la definición de ch'en que significa en varios idiomas mayas, incluyendo la escritura jeroglífica durante el período clásico, "un hoyo en la tierra" (Vogt y Stuart, 2005). Sin embargo, no existe ningún precedente para confirmar esta identificación ya que la grieta es única, como rasgo geológico, en el área 
maya. En las culturas mesoamericanas, las aperturas en la superficie de la tierra fueron lugares muy importantes como puntos de acceso a los antepasados y las entidades sobrenaturales. De hecho, algunos estudios arqueológicos han proporcionado evidencia de que las cuevas y otras formas de hoyos en la tierra fueron lugares donde se realizaron actividades rituales (Awe, 1998; Brady y Prufer, 2005; Prufer y Brady, 2005).

En otra publicación se ha argumentado sobre los motivos de construir Aguateca alrededor de la Grieta Principal como un axis mundi en el centro que enlazaba los tres niveles del universo, de acuerdo con un modelo cosmológico definido por los cuatro puntos cardinales (Ishihara, 2007: 13-16). Además de ese modelo, es posible que otro microcosmo o mapa del universo (Ashmore, 1991: 201) haya sido construido dentro de Aguateca, con base en la perspectiva de la familia real y familias del alto estrato social-político de la ciudad. Este segundo microcosmo se enfoca en los edificios residenciales y administrativos de esas familias, precisamente el Grupo Palacio, ubicado en un terreno angosto, un espacio restringido entre la escarpa y la Grieta Principal (Fig. 2). Desde esta ubicación, la grieta se encuentra al oeste, donde el sol se pone en el inframundo, y al este, el lago, donde sale el sol. Bajo esta composición, el área residencial de la élite estaba delimitada por el paso diario del sol, y el sitio completo se percibe como una representación del caparazón de una tortuga flotando en el mar primordial (Miller y Taube, 1993). En efecto, la configuración de los edificios enfatiza el mencionado microcosmo. Al norte de los complejos residenciales, se ubica el Grupo Palacio, en una elevación más alta que los del sur, con tres niveles de terrazas anchas que llevan hasta allí. Esta ubicación se enmarca en las ideas de Ashmore (1991), sobre la relación existente entre el diseño espacial y la orientación cosmológica. La dirección hacia el norte hace referencia al mundo celestial y ancestral, y el Grupo Palacio se adhiere a esta concepción física y conceptualmente. Esta ubicación también se relaciona con la dicotomía entre lo privado (el norte o arriba) y lo público (el sur o abajo), caracterizado por los distintos niveles de acceso.

Como parte del estudio en la Grieta Principal, excavaciones arqueológicas fueron realizadas en cinco diferentes áreas de la misma. En el Cerro Frío, nueve unidades fueron investigadas, ocho fueron excavadas y en una, sólo se realizó recolección de superficie (Figura 5, Foto 1). La mayoría de los artefactos de esta área fueron recolectados en la Unidad l, en la cámara abierta (Cámara 5) y en las Unidades 2 y 5 dentro de una pequeña cueva encima del Cerro Frío. Fueron muy pocos materiales culturales recolectados en las otras unidades. Inicialmente se creyó que el Cerro Frío era utilizado para actividades no-rituales ya que gran parte del área se encuentra al aire libre, expuesta al cielo, características opuestas a las de las cuevas, lugares comunes para realizar actividades rituales. También se sugirió que cuerpos humanos pudieron haber sido arrojados o accidentalmente caídos desde arriba como consecuencia de las batallas que supuestamente ocurrieron durante el asalto a Aguateca. Además, debido a la ubicación del Cerro Frío adyacente a los edificios residenciales reales, se supuso que la basura cotidiana de los residentes era tirada en la grieta, teniendo como resultado un basurero. Sin embargo, los datos arqueológicos del área del Cerro Frío y la Grieta Principal no confirmaron ninguna de las dos hipótesis mencionadas. Al contrario, la evidencia arqueológica apunta hacia la realización de una variedad de actividades rituales que incluían ofrendas de vasijas cerámicas, quema de incienso, entierro de individuos o partes del cuerpo humano, entre otras (Ishihara, 2007; Palomo, 2007).

A pesar del tamaño pequeño de la cueva en la cima del Cerro Frío, aproximadamente $1 \mathrm{~lm}^{2}$, ésta contenía una cantidad mayor de artefactos con relación a la unidad de excavación en la cámara abierta. Esto puede ser el resultado de un uso más intenso de la cueva, como lugar con alguna importancia para depositar materiales des- 
pués de actos rituales. Un dato interesante es que fueron encontrados tiestos que probablemente pertenecieron a una misma vasija en la cueva y en la cámara, lo que sugiere una fluidez más dinámica en el uso del espacio en la reconstrucción de las prácticas ceremoniales. En cuanto al período de uso, casi todas las cerámicas del Cerro Frío datan del clásico tardío, especialmente de la fase tardía (ca. 760 - 810 d.c.) (Ishihara, 2007: 203-205).

\section{Características topográficas}

El Cerro Frío es un cerro con inclinaciones empinadas por el norte y por el sur (Foto 1). En la cumbre del cerro existe una cueva cubierta con unas losas grandes en forma de colina, la cual expresa el concepto Maya de cueva-montaña (Stone, 1995: 32-34). Las cuevas son consideradas como la parte interior hueca de los cerros (Schele y Freidel, 1990: 60). Por ejemplo, el glifo witz que significa "cerro" o "montaña" frecuentemente tiene una cueva representada por una apertura en la parte de arriba o al frente en el caso del witz zoomórfico (Stuart, 1987: 17-23).

El ascenso hacia la cima del cerro, que mide 63 metros de largo con 40 grados de inclinación, es uno de los más agotadores dentro de la grieta. El ascenso al cerro es similar a los peregrinajes contemporáneos a la cima de cerros y cuevas para visitar altares y realizar ritos, muchos de los cuales son para pedir lluvias (BassieSweet, 2002; Gurnee, et al. 1968: 167; Oakes, 1951: 74). Posiblemente esto se relaciona con la creencia de los Mopanes de que los Chaaks, las deidades de la lluvia, residen en las cumbres de los cerros (Thompson, 1930: 62). Es posible que, durante el período clásico tardío, los participantes en las ceremonias ascendieran al Cerro Frío con el fin de saludar a los espíritus de la cueva y realizar ritos. Tales ritos pudieron haber sido realizados durante el día o la noche dado que la luz del sol o la luna iluminan la cámara abierta. Es importante destacar que al contrario de las montañas situadas en la superficie de la tierra, la topografía única de la cueva-montaña dentro de la grieta, la cual forma parte del mundo de los antepasados y entidades sobrenaturales, puede ser importante en sí misma.

\section{Fenómenos naturales de las nubes y el viento}

La segunda característica importante del Cerro Frío proviene de la observación directa de un fenómeno natural realizada en abril del 2005. Cada media hora, suben nubes densas al cerro desde cualquiera de las dos pendientes al sur y al norte del área (Foto 2). De acuerdo con la geóloga Beverley Shade es probable que la causa de este fenómeno sea por las diferencias en temperatura dentro de la grieta y la superficie, así como la presencia de entradas múltiples en diferentes elevaciones, resultando en corrientes de aire pasando por la grieta (Ishihara, 2007: 42; Ishihara, et. al. 2004: 6.12-6.13). Este fenómeno no es único, actividades similares han sido observadas y documentadas en la Cueva de Petroglifo en Belice (MacLeod y Puleston, 1979: 73, fig.l). A partir de la experiencia en la Grieta Principal, la creencia indígena de que las nubes se crean en las cuevas tiene sentido (Gossen, 1974: 21; Guiteras-Holmes, 1961: 287), al igual que las creencias tzotziles y tzeltales documentadas por Groark (1997: 25) quienes consideran que "Las nubes de lluvia crecen en el corazón de las montañas huecas, luego salen, embarazadas con lluvia, desde la boca de las cuevas". Los vientos bi-direccionales de la Grieta Principal concuerdan con la idea de que las deidades principales del viento son entidades cuadripartidas, semejantes a los dioses de la lluvia (Thompson, 1970: 271-272). Además, descripciones etnográficas cuentan que las divinidades asociadas con la lluvia moran en las cuevas y los cenotes (Holland, 1963: 93; Villa Rojas, 1945: 103).

En cuanto al arte visual prehispánico, Chaak es representado frecuentemente en cuevas. Un buen ejemplo es una escultura de Chaak, de tamaño natural, sentado dentro de una cueva, hecha en piedra y estuco en El Petén, Guatemala (Stuart y Stuart, 1977: 53). Existen 
otras representaciones de Chaak en diferentes lugares asociados con cuevas, por ejemplo, Chaak dentro de zoormórfos de witz; Chaak con motivos de cueva en forma de cuatrifolio, es decir, un trébol con cuatro hojas; además de Chaak dentro de cenotes llenos de agua y en la lluvia (Coe, 1978: vasijas 4, 11; Graham, 1967: fig.61, Machaquilá, Estela 10; Códice de Dresde, páginas 30a, 34c, 38c).

En el Cerro Frío, además de la aparición de las nubes, se puede observar un viento fresco y relativamente fuerte que sopla las nubes. Existen creencias de que el viento saliendo de las entradas de las cuevas sirve como prueba del aliento de las mismas, ya que las cuevas son consideradas entidades vivas y animadas (Garza, 2003; Taube, 2001: 105). Para los Tzotziles, el viento que sopla sobre la tierra es el aliento de Anhel (ángel), la deidad de la lluvia quien reside en cuevas (Holland, 1963: 93). Taube (2004: 73-74) identificó el dios maya del viento como la personificación del viento, el aliento y el espíritu del aliento, quien es representado típicamente por un joven con aretes que lleva el signo ik' (en la forma de T) y una flor prominente en la frente $\mathrm{o}$, a veces, como parte de una cinta tejida de pelo (Taube, 2001: 109), la cual es "un indicador de artesano de la corte" (Taube, 2004:74). Asimismo, el dios del viento también es la deidad de la música, quien es representada llevando una sonaja en la mano e instrumentos de música simbolizando flores y elementos asociados con el viento. De hecho, para los Ch'orti' en Guatemala, la sonaja (chinchin) es un instrumento asociado con la deidad de la lluvia (Girard, 1949: 308). La relación estrecha entre la lluvia y la música se puede observar en la creencia de los Teenek, o Huastecos de San Luis Potosí, México, que consideran a la deidad Maamlaab como el Gran Dueño de la lluvia y la música (Gallardo Arias, 2004: 12).

En descripciones etnográficas realizadas por Thompson (1970: 256, nota 2) y Wisdom (1940: 439), la lluvia y el viento son elementos inseparables, ya que el viento y los dioses del viento son los cargadores de las deidades de la lluvia quienes rocían el agua sobre la milpa. Además del rayo y el trueno, hay casos en los que el viento se encuentra en el ámbito del dios de la lluvia (Cline, 1944: 113; Thompson, 1930: 61). Por ejemplo, algunos miembros de la población indígena de San Andrés de la Cal, Morelos, México, piden a "los Señores del Tiempo" en las cuevas que hagan "los aires" que procrean la lluvia (Montoya Briones, 1975). De acuerdo con la historia oral de los Mopanes de Belice, un día un sirviente de Chaak llevó, en secreto, una bolsa de viento que pertenecía a Chaak. La bolsa, que es una herramienta adicional a la calabaza, el hacha y el tambor, al abrirse resultó una tormenta incontrolable (Thompson, 1930: 149). Existen otras evidencias que demuestran que en ceremonias para pedir una buena lluvia existen frecuentemente referencias a los dos dioses de la lluvia y del viento (Góngora Cámara y Preuss, 1990). Para los Lacandones de El Petén, Guatemala, se apela al viento para que "distribuya el polvo sobre las nubes para efectuar la lluvia" (Thompson, 1970: 271).

Al igual que las lluvias, también existen diferentes clases y géneros de viento. Dentro de las diferentes categorías existen los torbellinos que tienen importancia en el momento de quemar la milpa ya que "si no quema el monte por completo hasta que se transforme en ceniza fina, sería difícil o tal vez imposible sembrar la milpa" (Redfield y Villa Rojas, 1964: 133). Por lo tanto, para convocar esta clase de viento, el agricultor debe silbar una melodía (Redfield y Villa Rojas, 1964: 133-134). Asimismo, en San Andrés de la Cal, antes de llegar a la cueva, la encargada de la ceremonia toca un silbato para llamar a los espíritus, o a veces una trompeta (Huicochea, 1997: 243). Se cree que muchas de las relaciones existentes entre el viento, las nubes y la lluvia tienen origen en las cuevas y los cenotes (Redfield y Villa Rojas, 1964: 165); por lo tanto, es posible que la abundancia de los instrumentos de música recolectados en el Cerro Frío indiquen la práctica de invocar a las deidades de viento con quienes se comunicaban por medio de la música.

A través de representaciones iconográficas también es posible examinar la estrecha relación entre el viento 
y la lluvia. Según Thompson (1970: 257), en el Códice de Madrid (páginas 97c, 97d) (Matul y Fahsen, 2007) aparecen escenas en donde la vegetación crece en los signos de i $k$ ' sostenidos en las manos por varios dioses, incluyendo Chaak. Esto sugiere que glifo i $i$, que significa viento, también connota vida. A veces Chaak es representado llevando aretes cortados de concha Spondylus (Taube, 2004: 74), los cuales se relacionan con el torbellino (Taube, 2001: 111; 2003).

A través de escenas representadas en vasijas del periodo clásico tardío, Taube (2004) ha demostrado la conexión entre la lluvia y el viento en un episodio mítico donde Chaak captura al dios del viento en agua estancada (Coe, 1978: K595). Otro ejemplo relevante se encuentra en el Códice de Dresde (Códice de Dresde, 1983, página 44c), en el cual Chaak pesca una figura con pico de pato, muy parecido al dios del viento Ehecatl del valle central de México (Stuart, et al. 1999). Taube (2004: 77) ha sugerido que estos episodios míticos muestran el proceso transformativo natural del agua en lluvia. De manera interesante, el glifo descrito como "el pez en mano" y leido tzak, que significa "pescar", también significaba en Yucateco colonial "evocar las nubes y el viento" (Bolles, 1997). Curiosamente, se han documentado ceremonias de pesca, justo antes de la época de lluvias, realizadas por los chuj de Huehuetenango, Guatemala, y los zoques de Tabasco, México, en cuevas y pozos afuera de las mismas en temporadas secas específicas del año (Cobb, et al. 2008; Hose y Pisarowicz, 1999: 18). En particular, los autores comentan la creencia local de que los pescados de la cueva son un regalo especial de los dioses zoque, quienes habitan en el subterráneo.

Otra forma de explicar la relación entre el aire fresco y el agua es a través de las nociones etiológicas entre frío-caliente (Adams y Rubel, 1967), dualidad que algunos consideran tiene su origen en la cosmovisión indígena (Neuenswander y Souder, 1977). Se puede considerar que el ambiente fresco en el Cerro Frío abarca el concepto de lo frío, tanto el aire fresco circulando por los alrededores, como la temperatura de la tierra, así como el color blanco de las nubes (Mosquera Saravía y Kolstrup, 2006: 21-22). Por lo tanto, es posible creer que las ceremonias de la lluvia, esta última considerada fría, pudieron realizarse en un lugar con condiciones y características propicias para la invocación de las divinidades de la lluvia. Si se toma en cuenta la creencia de que el frío proviene de la noche, es posible pensar que algunas de las ceremonias de la lluvia fueran realizadas bajo la luz de la luna. Por último, la asociación entre el viento, la lluvia y las cuevas es representada en la Estela 3 de Ceibal ${ }^{1}$ (Graham, 1996: 17): en la parte inferior se encuentra el dios de viento con una sonaja y un tambor; en la parte superior están dos deidades de la lluvia quienes llevan una máscara con ojos y colmillos como los de Tlaloc; y, por último, en la parte central está un personaje parado frente de una cueva-montaña.

\section{Materiales arqueológicos Instrumentos musicales}

La Información acumulada en estudios arqueológicos, etnográficos y etnohistóricos han ayudado a reconstruir la clase de instrumentos musicales utilizados por los mayas en la época prehispánica. Se reconocen tres familias de instrumentos (Bourg, 2005: 7-8): 1) los aerófonos, o instrumentos de viento, que son los más comunes e incluyen ocarinas cerámicas, flautas de cerámica, hueso y junco, trompetas de madera y calabaza y caracoles grandes del género Strombus; 2) los membranófonos que consisten de tambores, los cuales producen sonido por una vibración de membrana tensada hecha de piel; y 3) los idiófonos sin membranas donde los sonidos son producidos por la vibración total del instrumento, y se incluyen sonajas de mano, tambores del caparazón de tortuga, raspadores de hueso, campanas de cerámica y "cascabeles" de concha Oliva, que también constituyen un tipo de collar.

En el conjunto arqueológico de la grieta, los instrumentos musicales son representados por tambores, 
flautas, ocarinas, todas de cerámica, y raspadores de hueso (Figura 7). Se encontraron tiestos policromos de tambores de cerámica, los cuales representan tambores portátiles que son agarrados con el brazo (Houston, et al. 2006: fig. 8.11). En la grieta, las ocarinas ${ }^{2}$ y las flautas componen la mayoría de las figurillas cerámicas (Tabla 1).

Al comparar por área la frecuencia de instrumentos musicales recolectados en la Grieta Principal, se reveló que la más alta concentración se encontró en el Cerro Frío (Tabla 1, Figura 6). Aunque la mayoría de fragmentos de tambores fueron recolectados en el Área de los Dos Búhos, el Cerro Frío tenía la segunda concentración más alta. Lo más importante es que casi todos los fragmentos de flautas y ocarinas provienen del Cerro Frío. Se descubrió casi la misma frecuencia de tambores y ocarinas en el espacio abierto y en la cueva; no obstante, todos los tiestos de las flautas fueron recolectados del interior de la cueva y en su entrada. Además, se excavó del interior de la cueva uno de los dos raspadores encontrados en toda la grieta (Figura 7, superior). En general, fueron muy pocos los instrumentos musicales documentados en las otras áreas de la grieta.

La distribución espacial de los instrumentos musicales reveló que la mayoría de ellos no fueron encontrados en lugares donde se esperaría se haya tocado la música, es decir, lugares con mucho espacio para tener movimiento asociado con la música. Por el contrario, pareciera que se seleccionaron espacios relativamente cerrados como el interior de la cueva del Cerro Frío para hacer música, quizá con la idea de aumentar los efectos acústicos. También es posible que las actuaciones musicales se hayan realizado en lugares abiertos, pero los instrumentos eran depositados en la cueva luego de su uso en ceremonias.

Como sabemos, la música es un elemento importante en ceremonias ya que ésta, en sí misma, constituye un tipo de ofrenda que sirve como medio de comunicación con los espíritus sobrenaturales y ancestrales y quienes, se cree "no son de la sustancia que consiste el mundo. Son, como dicen algunos indígenas, 'de viento"' (Redfield, 1941: 118). Se cree que los espíritus consumen el aroma del incienso y las flores, además de la música (Taube, 2001: 105; 2004: 73).

En imágenes prehispánicas se puede observar escenas de deidades, particularmente el dios de la lluvia y el dios del viento, tocando música en cuevas. Por ejemplo, en el mural de San Bartolo, El Petén, Guatemala, del período preclásico tardío, se observa al dios del maíz bailando y tocando un tambor dentro del caparazón de una tortuga (una cueva representada en forma cuatrifoliar) junto Chaak y al dios del agua estancada, la Serpiente Nenúfar (Saturno, et al. 2005). De la misma manera, en la Escultura 13l de Copán, Honduras, del clásico tardío, se representan cuatro entidades sobrenaturales, posiblemente los dioses del viento (Taube, comunicación personal, 2007), tocando sonajas y tambores dentro de una cueva en forma cuatrifoliar (Baudez, 1994: fig.72; Houston, et al. 2006: 264. fig. 8.16). En una vasija del mismo período (K530), se representan tres dioses de la lluvia haciendo música con un tambor de piso, un tambor de caparazón de tortuga y un raspador de cuerno de ciervo (Coe, 1978: lámina 11; Houston, et al. 2006: 265, fig.8.17). En esta escena, es posible que estos músicos se encuentren dentro de una cueva, ya que hay otro Chaak, quizá cantando, sentado frente a ellos dentro de un zoomórfo de witz (Taube, comunicación personal, 2007). En otra vasija (K4824) se sugiere el vínculo entre la música y la creación de la lluvia, vínculo que se representa por músicos con sonajas y raspadores de hueso a lado de una persona bailando en la lluvia (Kerr, 1994: 600). En el Códice de Dresde (página 34c) hay una representación de Chaak tocando un tambor, sentado encima de un witz, lo que probablemente significa la creación del trueno. Por esta razón, se especula que los tiestos de tambor encontrados en el área del Cerro Frío tiene un significado parecido. Para concluir con este argumento, en un estudio etnográfico sobre los Q'eqchi' de Alta Verapaz, Guatemala, se documentó la noción de deidades tocando música en cuevas (Brady, et al. 
2005: 221). De acuerdo con los informantes de Garza, los espíritus de la colina se reúnen, incluyendo el dueño de la misma, para tocar música con varios instrumentos, algunos, incluso, usando las estalagmitas y las estalactitas como tambores.

\section{Vasijas miniaturas}

Como parte de la parafernalia de la lluvia, Chaak lleva una calabaza o una tinaja (Thompson, 1930: 149; Tozzer, 1941: 163); se pueden observar calabazas pequeñas en descripciones contemporáneas de las deidades de la lluvia y en actividades relacionadas (Redfield y Villa Rojas, 1964:115, n.2). De hecho, existen creencias donde las calabazas y las tinajas son recipientes utilizados por las divinidades para rociar agua sobre la tierra (Holland, 1963: 93; Redfield y Villa Rojas, 1964: 139). Por ejemplo, en el Zoomorfo P de Quirigua, Izabal, Guatemala, un monumento del clásico tardío (Taube, 2003: fig.14b), se encuentran dos personajes de Chaak, cada uno con una tinaja en sus brazos, flotando en el aliento que sale de la boca de un cocodrilo terrestre, el cual metafóricamente representa una cueva. Otro ejemplo es un incensario recolectado en Mayapán, Yucatán, México, que representa a Chaak en su totalidad llevando una pequeña tinaja en la mano derecha (Thompson, 1957: fig.3f). La misma relación está representada en un conjunto de artefactos de la cueva de Balankanche, Yucatán, que consta de vasijas miniaturas, tinajas, cuencos y platos, manos y metates en miniatura, además de incensarios modelados con caras de Tlaloc, la deidad de la lluvia en México (Andrews, 1970). Según algunas creencias de indígenas de Morelos, México, la comida para las divinidades de la lluvia se sirve en platos pequeños ya que éstos son seres pequeños (Fierro, 2004: 341). La relación existente entre las vasijas miniatura y el concepto de hacer la lluvia está descrita por Schaafsma y Taube (2006: 256-258).

De las 28 vasijas miniaturas encontradas en la Grieta Principal, ocho fueron recolectadas del espacio abierto del Cerro Frío, seis de las cuales son tinajas de cuello angosto (tipo Tinaja Rojo y/o Pantano Impreso) mientras las otras dos son cuencos (tipo Tinaja Rojo e Infierno Negro) (Figura 8). Es posible que las tinajas en miniatura hayan tenido varias funciones, por ejemplo para guardar pigmentos (no se observó ningún vestigio visible en las vasijas del Cerro Frío). No obstante, se sugiere su uso en ceremonias de lluvia por algunas razones: en la actualidad se utilizan tinajas de cuello angosto como recipientes para llevar agua; la relación estrecha entre Chaak y las tinajas descrita anteriormente; y las tinajas policromas de cuello angosto recolectadas de la Gruta de Chac, Yucatán, que contienen símbolos pintados que significan agua (Andrews, 1965).

\section{Ofrendas de niños}

Además de las vasijas en miniatura, existe una relación entre los niños y niñas con las divinidades de la lluvia en los sacrificios (Schaafsma y Taube, 2006: 256-259). La ofrenda de bebés tiene origen en la fase Macayal (ca. 1200 a.C.), en El Manatí, Veracruz, México (Ortiz y del Carmen Rodríguez, 1999). De acuerdo con documentos etnohistóricos, en las tierras altas de Guatemala se llevaron niños y niñas a un nacimiento fuera de una cueva para ser sacrificados en nombre de la madre del agua (Fuentes y Guzmán, 1932), y en Yucatán, se le sacaron los corazones a niños y se tiraron en los cenotes como sacrificios a Chaak (Tozzer, 1941: 44, 119-120). En Teotihuacán, México, siete bebés fueron encontrados dentro de una de las cuevas, bajo un agujero en el techo donde se cree caía agua durante la temporada de lluvias; este hallazgo se interpreta como parte del rito en honor a Tlaloc (Manzanilla, 1994: 65). En el Estado de Morelos, México, varios antropólogos han documentado la percepción de un carácter infantil que tienen los aires que llevan la lluvia, los cuales son percibidos como niños o seres pequeños, tipo duendes (Juárez, 2007).

En el conjunto osteológico de la grieta, un número mínimo de 13 individuos fueron identificados como subadultos, de los cuales un cuarto fueron recupera- 
dos de la cueva del Cerro Frío. Dos subadultos desarticulados (los dos entre 4 y 8 años de edad) fueron representados por dos mandíbulas y una tibia; y otro subadulto o un adulto joven fue representado por una vértebra lumbar (Palomo, 2007: 109-114). La naturaleza secundaria del entierro de solamente algunos huesos de los subadultos puede indicar una clase específica de ofrenda. En la Cueva de Barton Creek, Belice, una alta proporción de niños menores de 12 años de edad (n=12) y adultos jóvenes (entre 18 a 34 años; $n=11$ de 31 individuos) fueron recolectados. Se interpretaron estos restos como sacrificios, ya que la distribución relativa de los niños menores de 12 años de edad excede la taza de mortalidad de la población general (Owen, 2005). Tanto Schaafsma y Taube (2006: 258) sugieren que la relación de las vasijas en miniaturas y niños pueden estar relacionadas al proceso vital del crecimiento, la germinación y el desarrollo de las plantas.

\section{Implicaciones sociales y políticas de las ceremonias de la lluvia}

Con base en creencias contemporáneas mayas sobre la importancia de la lluvia en el éxito agrícola, puede ser que las ceremonias de la lluvia fueran una de las más importantes actividades llevadas a cabo durante todo el año. De hecho, entre los ch'orti' de Guatemala, los hombres ancianos conocidos como Padrinos, son los personajes más importantes en la comunidad. Entre los Padrinos se encuentran los que se encargan de las ceremonias de la lluvia, los denominados horchanes ( $a h$ hor ca'n en ch'orti') o padrinos del agua. Estos personajes tienen permiso de Dios y las deidades nativas para hacer las ceremonias de la lluvia y su trabajo principal es atraer las lluvias al final de la estación seca o contenerlas si llueve demasiado (Wisdom, 1940: 374). Como se puede observar, además de los especialistas rituales que encabezaban las ceremonias, es probable que los músicos y danzantes tuvieran roles destacados, al igual que en ritos contemporáneos de la lluvia y en escenas de vasijas del período clásico (Gámez Espinosa, 2003: 46; Vogt, 1965: 41). De esta manera, la abundancia y variedad de instrumentos musicales hallados en el Cerro Frío indican que ciertas prácticas rituales incluían no sólo especialistas a cargo de las ceremonias sino también músicos y danzantes de acompañamiento. Es posible que los participantes en las ceremonias de la lluvia fueran de un estrato social alto, parecido al de los artesanos, los escribanos y los tallistas de estelas (Inomata, 2001), debido a su conocimiento especializado. referido como "un don de los dioses" por los Nahuas de la Huasteca Potosina de San Luis Potosí (Tiedje y Camacho, 2005: 140).

El estatus social de los participantes se puede identificar por el conjunto de artefactos asociados, lo mismo que por su ubicación espacial con relación al Cerro Frío. En primer lugar, la residencia y los edificios administrativos de la familia real del Grupo Palacio fueron construidos adyacentes al Cerro Frío, la proximidad indica el acceso restringido a individuos de un estatus alto asociado con la realeza. Es probable que las ceremonias realizadas en el Cerro Frío fueran llevadas a cabo como parte de ceremonias grandes y relativamente públicas en la plaza del Grupo Palacio. En segundo lugar, el estatus social también se relaciona con los instrumentos de música recolectados en el Cerro Frío. Ciertos bienes de alta calidad fueron encontrados, tales como fragmentos de vasija, tipo Negro Fino con inciso, posiblemente importado del Valle del Usumacinta. También se encontró un tiesto de un vaso hecho de piedra blanca, con texto de glifos fragmentados, con inciso en diagonal (Taube y Houston, comunicación personal, 2007), el cual es un artefacto raro en el área maya, por lo tanto, asociado a contextos de las élites (Luke, 2007). Este constituye sólo uno de los tres tiestos recolectados en todas las investigaciones de Aguateca (Inomata, 1995: 599, figs.8.47a, b). Además, la incidencia de casi todos los fragmentos de flautas en el Cerro Frío puede significar el estatus social alto de sus dueños, ya que constituyen 
una parte del conjunto musical formal representado en escenas de la corte en murales y vasijas policromas (Houston, et al. 2006: 258-267; Miller, 1988).

Una comparación con una cueva de la misma región de Petexbatún es útil para indagar más sobre el estatus social de los participantes de las actividades rituales. Brady y Rodas (1995) sugieren que los depósitos de artefactos en la Cueva de Los Quetzales, una cueva cercana a Dos Pilas, de los cuales se obtuvieron una alta frecuencia de instrumentos musicales (más de 300 tiestos de tambor y 51 silbatos/ocarinas completas o fragmentadas), representan actividades llevadas a cabo por gente de un estatus social alto, debida a su ubicación a la acrópolis de Las Pacayas ubicada directamente encima de la cueva, con la entrada de la cueva cerca del centro de la plaza. De hecho, la configuración espacial es parecida a la del Cerro Frío y el Grupo Palacio.

Si las ceremonias de la lluvia fueron realizadas en el Cerro Frío como se ha sugerido anteriormente, éstas pudieron haber tenido implicaciones políticas para la élite y la familia dinástica de Aguateca. En este contexto, el manejo del agua era decisivo en la vida de la gente por su dependencia de la agricultura. Por lo tanto, el control sobre este recurso seguramente jugó un papel de mucha importancia en la aparición y el mantenimiento del liderazgo político en el área maya (Lucero y Fash, 2006; Scarborough, 2003). Es posible que la lluvia fuera vinculada con la autoridad y el poder sobre la población en general, y en las ceremonias se pidiera no sólo por las lluvias y la fertilidad agrícola sino por el crecimiento de la dinastía y la prosperidad. ${ }^{3}$

En particular se debe destacar el contexto temporal de las actividades rituales realizadas en el Cerro Frío. La incidencia frecuente de los tipos cerámicos asociados con la fase tardía del período clásico tardío en Aguateca (760-810 d.C.) indica su uso después del año 760 d.c. hasta el deceso de la entidad política en la parte temprana del siglo nueve (Ishihara, 2007: 204-205, Tablas 7.11-7.13). El año 761 d.c. es importante en la historia política de Dos Pilas y Aguateca ya que en ese momento el gobernante K'awiil Chan K'inich fue exilado por el competidor de Tamarindito, un proceso que determinó al abandono general de Dos Pilas (Fahsen, 2003; Houston, 1993; Martin y Grube, 2000: 63). Después de este incidente, el rey Tan Te' K'inich, se convirtió en el Gobernante de Aguateca, y Aguateca se hizo la capital primaria. Las murallas defensivas probablemente fueron construidas durante esta época cuando las tensiones políticas iban en aumento (Inomata, 1995: 838), lo que repercutió para una re-organización de los espacios y actividades en el sitio (Ishihara, 2007: 312).

Otra implicación importante de las ceremonias de la lluvia es la asociación del dios de la lluvia Chaak con la guerra. Chaak es regularmente representado como un guerrero, llevando en su equipo un hacha de rayo y un escudo (Taube, 1992: fig.6a). De la misma manera, gobernantes victoriosos son comúnmente representados llevando un tocado de Chaak, como se observa en la Estela 1 (74l d.C.) de Aguateca, la cual conmemora el ascenso al trono de K'awiil Chan K'inich días después de la muerte de su predecesor. Es posible que los últimos gobernantes de la dinastía, K'awiil Chan K'inich y Tan Te' K'inich, pudieron haber realizado ceremonias de la lluvia en la grieta, presentándose como Chaak, el que trae la lluvia y el guerrero, particularmente cuando reinaba la confusión política en la región Petexbatún. También es posible que se haya invocado en las ceremonias al gobernante fundador de la dinastía, B'alaj Chan K'awiil, ya que su nombre significa "K'awiil da martillazos (en) el cielo," k'awiil representando el hacha portada por Chaak (Guenter, 2003: 2).

\section{Conclusión}

Tanto los materiales arqueológicos, los rasgos topográficos y los fenómenos naturales observados en el Cerro Frío de la Grieta Principal de Aguateca, sirvie- 
ron en su conjunto como evidencias para reconstruir una clase de ceremonias que pudieron haber sido realizadas en los espacios subterráneos. La evidencia también presenta una ventana para entender la importancia de las actividades rituales llevadas a cabo dentro de la tierra en relación al ciclo de las lluvias, el viento y su relevancia con la agricultura, todas vinculadas entre sí a través de dos elementos clave de la cosmovisión maya: el agua (lluvia) y el aire (viento). En el caso de Aguateca, es probable que el Cerro Frío haya constituido un lugar idóneo dentro de la tierra, donde el aire sopla desde el fondo de la grieta creando nubes, para realizar ceremonias para la lluvia donde se tocaban instrumentos musicales y se quemaban ofrendas en nombre de los dioses. Igual de probable fue la utilización y quema de incienso de copal, para crear humo negro y semejar nubes de lluvia. Todo con la esperanza de hacer llover. En Aguateca, la relación de las personas con estos elementos clave para la vida fue materializada en la forma de ceremonias de la lluvia, que integraban significados adicionales especiales vinculados a la prosperidad de la agricultura, la dinastía y el poder de los gobernantes. Es importante recordar que el Cerro Frío en Aguateca se utilizó como lugar de ritos después del abandono general de Dos Pilas y la conversión de Aguateca como la capital primaria.

\section{Agradecimientos}

El presente estudio tiene su origen en mi investigación doctoral que formó parte del Proyecto Arqueológico Aguateca, dirigido por Dr. Takeshi Inomata, Dra. Daniela Triadan y Mtro. Erick Ponciano, con la autorización de la Dirección General del Patrimonio Cultural y Natural del Ministerio de Cultura y Deportes de Guatemala y que fuera financiado por la Beca para el Mejoramiento de la Disertación de la Fundación Nacional de las Ciencias (NSF en inglés) (SBE-0431332); la Beca de Investigación para Postgraduados de la NSF; la
Beca de Investigación para Postgraduados en Estudios Kársticos y de Cuevas de Ralph W. Stone de la Sociedad Nacional de Espeleología de los Estados Unidos; y la Beca para Disertación de la Universidad de California en Riverside. Una versión anterior del presente artículo fue presentada en la lra Conferencia de Maya en la Playa que se llevó a cabo en Palm Coast, Florida, EEUU, en mayo del 2007. Asimismo, una versión más breve fue publicada en inglés en la revista World Archaeology del Reino Unido, que recibió comentarios del Dr. Karl Taube, Dr. Takeshi Inomata y Dr. Jim Brady. Para ellos mi agradecimiento. Además les agradezco a los dos dictaminadores. También agradezco a Carlos Pérez-Brito por su tiempo editando el artículo. Por último, las ideas y errores que pudieran aparecer en este artículo son enteramente mi responsabilidad.

\section{Notas}

${ }^{1}$ Agradezco a la Dra. Christina Halperin por mostrarme el ejemplo de la Estela 3 de Ceibal. Septiembre 2007.

${ }^{2}$ Cabe aclarar que las ocarinas son instrumentos que tienen una o más cámaras resonantes con agujeros para producir varias notas, mientras los silbatos son instrumentos con un solo agujero que producen una sola nota (Lee 1969, citado en Hammond 1972: 226; ver también Bourg 2005:10). Las flautas son parecidas a las ocarinas, sólo que la cámara resonante es larga y en forma cilíndrica. Los raspadores son hechos del hueso largo de algún animal grande o humano y tienen una serie de incisiones paralelas sobre las cuales se frota otro objeto para producir sonido.

${ }^{3}$ La preocupación por la administración del agua puede ser detectado en el atuendo de Tan Te' K'inich en la Estela 7 (790 d.C.) de Aguateca, el cual lleva adornos en los pies que representan la Serpiente Nenúfar, la deidad del agua estancada (Ishihara, et al. 2006). Quizá esta representación simboliza su control sobre (o por lo menos la ambición de dominar) la Laguna Petexbatún sobre la cual Aguateca tiene vista. 


\section{Bibliografía}

Códice de Dresde (1983), México: Fondo de Cultura Económica.

Adams, Richard N. y Arthur J. Rubel (1967), "Sickness and social relations", en M. Nash (ed), Handbook of Middle American Indians, vol. 6: Social Anthropology, Austin: Ed. Universidad de Texas, pp. 333-356.

Andrews, E. Wyllys, IV (1970), Balankanche, throne of the Tiger Priest, publicación 32. Nueva Orleans: Middle American Research Institute, Universidad de Tulane.

Ashmore, Wendy (1991), "Site-planning principles and concepts of directionality among the ancient Maya", en Latin American Antiquity, vol. 2, núm. 3, pp. 199 226.

Awe, Jaime J. [ed], (1998), The Western Belize Regional Cave Project: a report of the 1997 field season, Documentos Ocasionales, núm. 1, Durham: Departamento de Antropología, Universidad de Nueva Hampshire.

Bassie-Sweet, Karen (2002), The Jolja' Cave Project, informe entregado a la Fundación para el Avance de Estudios Mesoamericanos, Crystal River.

Baudez, Claude F. (1994), Maya sculpture of Copan: the iconography, Ed. Universidad de Oklahoma, Norman.

Bolles, David (1997), "Combined dictionary-concordance of the Yucatecan Mayan language", en http:// www.famsi.org/reports/96072/index.html, [Mayo de 2007].

Bourg, Cameron H. (2005), Ancient Maya music now with sound, tesis de maestría, Universidad Estatal de Louisiana, Baton Rouge.

Brady, James E. y Wendy Ashmore (1999), "Mountains, caves, water: ideational landscapes of the ancient Maya", en W. Ashmore y A. B. Knapp (eds), Archaeologies of Landscape: Contemporary Perspectives, Ed. Blackwell, Malden, pp. 124-145.

Brady, James E., Allan Cobb, Sergio Garza, Cesar Espinosa y Robert Burnett (2005), “An Analysis of Ancient Maya
Stalactite Breakage at Balam Na Cave, Guatemala", en K. M. Prufer y J. E. Brady (eds), Stone houses and earth lords: Maya religion in the cave context, Colorado: Ed. Universidad de Colorado, Boulder, pp. 213-225.

Brady, James E. y Keith M. Prufer [eds], (2005), In the maw of the earth monster: Mesoamerican ritual cave use, Austin: Ed. Universidad de Texas.

Brady, James E. y Irma Rodas, (1995), "Maya ritual cave deposits: recent insights from the Cueva de Los Quetzales", en Institute of Maya Studies Journal, vol. 1, núm. 1, pp. 17-25.

Cline, Howard F. (1944), "Lore and deities of the Lacandon Indians", en Journal of American Folklore, vol. 57, pp. 107-115.

Cobb, Allan, Sergio Garza y James E. Brady (2008), "Caves and fish in Mesoamerica: an initial consideration", en ponencia presentada en la Conferencia Anual de la Sociedad para la Arqueología Americana, Vancouver, marzo de 2008.

Coe, Michael D. (1978), Lords of the underworld: masterpieces of Classic Maya Ceramics, Princeton: Ed. Universidad de Princeton.

de Fuentes y Guzmán, Francisco Antonio (1932), Recordación florida: discurso historical y demostración natural, material, militar y politica del reyno de Goathemala, vols 6-8, Guatemala: Biblioteca Guatemala.

Fahsen, Federico (2003), "Rescuing the origins of Dos Pilas dynasty: a salvage of Hieroglyphic Stairway \$2, Structure L5-49", informe entregado a la Fundación para el Avance de Estudios Mesoamericanos, Crystal River.

Fierro, Ulises (2004), "Culto en Cueva Santa: una perspectiva histórica y etnográfica (Atlacholoaya, Morelos)”, en J. Broda y C. Good Eshelman (eds), Historia y vida ceremonial en las comunidades mesoamericanas: los ritos agrícolas, México: INAH, UNAM, pp. 339-350.

Gallardo Arias, Patricia (2004), Huastecos de San Luis Potosí, México: Comisión Nacional para el Desarrollo de los Pueblos Indígenas.

12 Revista LiminaR. Estudios sociales y humanísticos, año 7, vol. VII, núm. 1, junio de 2009, Tuxtla Gutiérrez, Chiapas, México. ISSN: 1665-8027 
Gámez Espinosa, Alejandra (2003), "El ciclo agrícola ritual en una comunidad popoloca del sur de Puebla", en Revista de la Facultad de Filosofia y Letras, vol. 2, pp.39-53.

Gann, Thomas W. F. (1968), "The Chachac, or rain ceremony, as practised by the Maya of southern Yucatan and northern British Honduras", en F. W. Hodge (ed), Proceedings of the nineteenth international congress of Americanists, 1915, Nendeln/ Liechtenstein, Kraus Reprint, pp. 409-418

Garza, Sergio (2003), "An ethnoarchaeological approach to Maya caves", en ponencia presentada en la Conferencia Annual de la Sociedad para la Arqueología Americana, Milwaukee, abril de 2003.

Girard, Rafael (1949), Los Chortis ante el problema Maya: historia de las culturas indígenas de América, desde su origen hasta hoy, México: Librería de Manuel Porrúa.

Góngora Cámara, José y Mary H. Preuss (1990), “A Yucatec-Mayan prayer for rain from the ch'aa chaac ritual", en Latin American Indian Literatures Journal, vol. 6, pp.130-144.

Gossen, Gary H. (1974), Chamulas in the world of the sun. Cambridge: Ed. Universidad de Harvard.

Graham, Ian (1967), Archaeological explorations in El Petén, Guatemala, Publicación 33. Nueva Orleans: Middle American Research Institute, Universidad de Tulane.

Graham, Ian, (1996), Corpus of Maya hieroglyphic inscriptions, vol. 7, part 1: Seibal, Cambridge: Peabody Museum of Archaeology and Ethnology, Universidad de Harvard.

Groark, Kevin P., (1997), "To warm the blood, to warm the flesh: the role of the steambath in Highland Maya (Tzeltal-Tzotzil) ethnomedicine", en Journal of Latin American Lore, vol. 20, núm. 1, pp. 3-95.

Guenter, Stanley P. (2003), "The inscriptions of Dos Pilas associated with B'ajlaj Chan K'awiil", en Mesoweb, www.mesoweb.com/features/guenter/ DosPilas.pdf.
Guiteras-Holmes, Calixta (1961), Perils of the soul: the world view of a Tzotzil Indian, Ed. Free, Nueva York.

Gurnee, Russell H., Ward Randol, A. Richard Smith, Richard Gould, G. Nicholas Sullivan, Charles E. Mohr, Hugh Land y José Limeres, 1968, "Mayan cave discoveries", en Explorers Journal, vol. 46, núm. 3, pp. 146-186.

Hammond, Norman (1972), Classic Maya music, part II, rattles, shakers, raspers, wind and string instruments, en Archaeology, vol. 25, pp. 222-228.

Holland, William R. (1963), Medicina Maya en los altos de Chiapas, Instituto Nacional Indigenista, México.

Hose, Louise D. y James A. Pisarowicz, (1999), “Cueva de Villa Luz, Tabasco, Mexico: reconnaissance study of an active sulfur spring cave and ecosystem", en Journal of Cave and Karst Studies, vol. 61, núm. 1, pp. 13-21.

Houston, Stephen D. (1993), Hieroglyphs and history at Dos Pilas: dynastic politics of the Classic Maya, Austin: Ed. Universidad de Texas.

Houston, Stephen D., David Stuart y Karl Taube (2006), The memory of bones: body, being, and experience among the Classic Maya, Austin: Ed. Universdad de Texas.

Huicochea, Liliana (1997), "Yeyecatl - Yeyecame: petición de lluvia en San Andrés de la Cal", en J. Broda y B. Albores (eds), Graniceros. Cosmovisión y meteorología indígena de Mesoamérica, México: UNAM, pp. 233-254.

Inomata, Takeshi (1995), Archaeological investigations at the fortified center of Aguateca, El Petén, Guatemala: implications for the study of the Classic Maya collapse, tesis doctoral, Nashville: Universidad de Vanderbilt.

Inomata, Takeshi (1997), "The last day of a fortified Classic Maya center: archaeological investigations at Aguateca, Guatemala", en Ancient Mesoamerica, vol. 8, pp.337-351. 
Inomata, Takeshi (2001), "The power and ideology of artistic creation”, en Current Anthropology, vol. 42, núm. 3, pp. 321-349.

Ishihara, Reiko (2007), Bridging the chasm between religion and politics: archaeological investigations of the grietas at the Late Classic Maya site of Aguateca, Peten, Guatemala, tesis doctoral, Riverside: Universidad de California.

Ishihara, Reiko, Jenny Guerra, Beverly Shade, Nicholas Johnson, Douglas Weinberg, Ana Cristina Morales, María de los Angeles Corado y Michael Mirro (2004), "Levantamiento de mapa de la grieta", en E. Ponciano, D. Triadan y T. Inomata (eds), Informe del proyecto arqueológico Aguateca segunda fase: la temporada de campo de 2004, Informe entregado al Instituto de Antropologia e Historia de Guatemala, pp. 6.1-6.36.

Ishihara, Reiko, Karl Taube y Jaime Awe (2006), "The Water Lily Serpent stucco masks at Caracol, Belize", en J. Morris, S. Jones, J. Awe y C. Helmke (eds), Archaeological investigations in the eastern Maya Lowlands: papers of the 2005 Belize archaeology symposium, Research Reports in Belizean Archaeology Vol. 3, Belmopan: Instituto de Arqueología de Belice, pp. 213-223.

Juárez Becerril, Alicia María (2007), “'Los niños del viento': El concepto de infancia en un elemento meteorológico de la región de Tepoztlán, Morelos”, en D. Robichaux (ed), México: Consejo Latinoamericano de Ciencias Sociales - CLACSO.

Kerr, Justin [ed], (1994), The Maya vase book, vol.4. Nueva York: Kerr Asociados.

Lee, Thomas A., Jr. (1969), The artifacts of Chiapa de Corzo, Chiapas, Mexico. Papers of the New World Archaeological Foundation 26, Provo.

López Medel, Tomás (1612), “Appendix B: de los tres elementos, aire, agua, i tierra en que se trata de las cosas que en cada uno de ellos, acerca de las occidentales indios naturales", en A. M. Tozzer (ed), Landa's relacion de las cosas de Yucatan: a translation, Papeles de Múñoz, 42. Madrid: Academia de Historia.
Lucero, Lisa J. y Barbara W. Fash [eds], (2006), Precolumbian water management: ideology, ritual, and power, Tucson: Ed. Universidad de Arizona.

Luke, Christina (2007), "Carving luxury: Late Classic white stone vase traditions in Mesoamerica”, en Y. M. Rowan y J. R. Ebeling (eds), New approaches to old stones: recent studies of ground stone artifacts, Londres: Equinox, pp. 298-319.

MacLeod, Barbara y Dennis Puleston (1979), "Pathways into darkness: the search for the road to Xibalba", en M. G. Robertson y D. C. Jeffers (eds), Third Palenque Round Table, 1978, Part 1, Palenque Mesa Redonda Serie 4. Pre-Columbian Art Research Institute \& Herald Printers, Palenque \& $\&$ Monterey, pp. 71-78.

Manzanilla, Linda (1994), "Las cuevas en el mundo mesoamericano”, Ciencias, vol. 36, octubre-diciembre, pp.59-66.

Martin, Simon y Nikolai Grube (2000), Chronicle of the Maya kings and queens: deciphering the dynasties of the ancient Maya, Londres: Thames \& Hudson.

Matul, Daniel y Federico Fahsen (2007), Códice de Madrid (Tro-Cortesiano), Tz'ib' rech Madrid, Guatemala: Amanuense Ed.,

Miller, Mary (1988), "The boys in the Bonampak band", en E. P. Benson y G. G. Griffin (eds), Maya Iconography, Princeton: Ed. Universidad de Princeton, pp. 318-330.

Miller, Mary y Karl Taube (1993), An illustrated dictionary of the gods and symbols of ancient Mexico and the Maya", Londres: Thames \& Hudson.

Montoya Briones, José de Jesús (1975), "El complejo de los aires en la cosmología de los nahuas de Puebla", en Boletin del INAH, Epoca II, abril-junio, México, pp.53-58.

Morehart, Christopher (2002), Ancient Maya ritual cave utilization: paleoethnobotanical perspective, tesis de maestría, Universidad Estatal de Florida, Tallahassee.

Mosquera Saravía, María Teresa y Nils Kolstrup (2006), La comunicación entre paciente y trabajadores de 
salud en una sociedad multiétnica", Guatemala: Instituto de Estudios Interétnicos, Unviersidad de San Carlos de Guatemala.

Moyes, Holley (2006), The sacred landscape as a political resource: a case study of ancient Maya cave use at Chechem Ha Cave, Belize, Central America", tesis doctoral, Buffalo: Universidad Estatal de Nueva York.

Neuenswander, Helen L. y Shirley Souder (1977), "The hot-cold wet-dry syndrome among the Quiché of Joyabaj: two alternative cognitive models", en H. L. Neuenswander y D. E. Arnold (eds), Cognitive studies of southern Mesoamerica, Dallas: Summer Institute of Linguistics, pp. 96-125.

Oakes, Maud (1951), The two crosses of Todos Santos, survivals of Mayan religious ritual, Nueva York: Pantheon Books.

Ortiz, Ponciano y María del Carmen Rodríguez (1999), "Olmec ritual behavior at El Manatí: a sacred space", en D. C. Grove y R. A. Joyce (eds), Social patterns in Pre-classic Mesoamerica, Washington, D.C: Dumbarton Oaks, pp. 225-254

Owen, Vanessa A. (2005), "A question of sacrifice: Classic Maya cave mortuary practices at Barton Creek Cave, Belize”, en K. M. Prufer y J. E. Brady (eds), Stone houses and earth lords: Maya religion in the cave context, Ed. Universidad de Colorado, Boulder, pp. 323-340.

Palomo, Juan. Manuel, (2007), Muerte, cerro y cueva: la bioarqueología de las grietas en Aguateca, tesis de licenciatura, Guatemala: Universidad de San Carlos.

Ponciano, Erick M., Daniela Triadan y Takeshi Inomata [eds], (2004), Informe del proyecto arqueológico Aguateca, segunda fase: la temporada de campo de 2004, Guatemala: informe presentado al Instituto de Antropología e Historia de Guatemala.

Ponciano, Erick M., Daniela Triadan y Takeshi Inomata [eds], (2005), Informe del proyecto arqueológico Aguateca, la temporada de campo 2005, Guatemala: informe presentado al Instituto de Antropología e Historia de Guatemala.
Prufer, Keith M. y James E. Brady [eds], (2005), Stone houses and earth lords: Maya religion in the cave context, Ed. Universidad de Colorado, Boulder.

Redfield, Robert (1941), The folk culture of Yucatan, Chicago: Ed. Universidad de Chicago.

Redfield, Robert y Alfonso Villa Rojas (1964), Chan Kom: a Maya village, originalmente publicado en 1934, Chicago: Universidad de Chicago.

Rissolo, Dominique (2005), "Beneath the Yalahau: emerging patterns of ancient Maya ritual cave use from northern Quintana Roo, Mexico", en J. E. Brady y K. M. Prufer (eds), In the maw of the earth monster: Mesoamerican ritual cave use, Austin: Ed. Universidad de Texas, pp. 342-372.

Saturno, William, David Stuart y Karl Taube (2005), "La identificación de las figuras del Muro Oeste de pinturas Sub-1, San Bartolo, Peten", en J. P. Laporte, B. Arroyo y H. Mejia (eds), XVIII Simposio de Investigaciones Arqueológicas en Guatemala, 2004, Guatemala: Instituto de Antropología e Historia, pp. 646-655.

Scarborough, Vernon L. (2003), The flow of power: ancient water systems and landscapes, Santa Fe: School of American Research.

Schaafsma, Polly y Karl A. Taube (2006), "Bringing the rain: an ideology of rain making in the pueblo Southwest and Mesoamerica", en J. Quilter (ed), A Pre-Columbian world: searching for a unitary vision of ancient America, Octubre 6 y 7,2001 , Washington, D.C.: Dumbarton Oaks, pp. 231-285.

Schele, Linda y David Freidel (1990), A forest of kings: the untold story of the ancient Maya, Nueva York: William y Morrow.

Scholes, Frances V. y Eleanor B. Adams (1938), Don Diego Quijada, alcalde mayor de Yucatán, 15611565, 2 vols. México: Antigua librería Robredo, de J. Porrúa e Hijos.

Stone, Andrea (1995), Images from the underworld: Naj Tunich and the tradition of Maya cave painting, Austin: Ed. Universidad Texas. 
Stuart, David (1987), Ten phonetic syllables, Research reports on ancient Maya writing, No.14, Washington, D.C.: Center for Maya Research,

Stuart, David y Stephen Houston, (1994), Classic Maya place names, Studies in Pre-Columbian Art and Archaeology, No. 33, Washington, D.C.: Dumbarton Oaks,

Stuart, David, Stephen Houston y John Robertson (1999), "Recovering the past: Classic Maya language and Classic Maya gods", en Notebook for the 23rd Maya hieroglyphic forum at Texas, Austin: Maya Workshop Foundation.

Stuart, George E. y Gene S. Stuart (1977), The mysterious Maya, Washington, D.C.: National Geographic Society.

Taube, Karl A. (1992), The major gods of ancient Yucatan, Studies in Pre-Columbian art and Archaeology, vol. 32, Washington, D.C.: Dumbarton Oaks.

Taube, Karl A. (2001), "The breath of life: the symbolism of wind in Mesoamerica and the American Southwest", en V. M. Fields y V. Zamudio-Taylor (eds), The road to Aztlan: art from a mythic homeland, Los Angeles: Los Angeles County Museum of Artpp, 102-123.

Taube, Karl A., (2003), "Maws of Heaven and Hell: The Symbolism of the Centipede and Serpent in Classic Maya Religion", en A. C. Ruiz, M. H. Ruz Sosa y M. J. I. Ponce de León (eds), Antropología de la eternidad: la muerte en la cultura Maya, Madrid \& México: Sociedad Española de Estudios Mayas \& El Centro de la Cultura Maya, pp. 405-442.

Taube, Karl A. (2004), "Flower mountain: concepts of life, beauty, and paradise among the Classic Maya", en RES: Anthropology and Aesthetics, vol. 45, Spring, pp.69-98.

Thompson, J. Eric (1930), Ethnology of the Mayas of southern and central British Honduras, Publicación 274, Anthropological Series 17, núm.2. Chicago: Field Museum of Natural History.

Thompson, J. Eric (1957), "Deities portrayed on censers at Mayapan", en Current Report, vol. 40, Washington, D. C., pp.599-632.

Thompson, J. Eric (1970), Maya history and religion, Ed. Universidad de Oklahoma, Norman.

Tiedje, Kristina y G.onzalo Camacho, (2005), "La música del arpa entre los nahuas de la Huasteca, simbolísmo y aspectos performativos", en Anales de Antropología, vol. 39, núm. 2, pp.131-163.

Tozzer, Alfred M. (1941), Landa's relacion de las cosas de Yucatan: a translation, Papers of the Peabody Museum of Archaeology and Ethnology 18, Cambridge: Universidad de Harvard.

Villa Rojas, Alfonso, (1945), The Maya of east central Quintana Roo, Publicación 599, Washington, D.C.: Carnegie Institution of Washington.

Vogt, Evon Z. (1965), "Ceremonial organization in Zinacantan”, en Ethnology, vol. 4, núm. 1, pp.39-52.

Vogt, Evon Z. y David Stuart (2005), "Some Notes on Ritual Caves among the Ancient and Modern Maya", en J. E. Brady and K. M. Prufer (eds), In the maw of the earth monster: Mesoamerican ritual cave use, Austin: Ed. Universidad de Texas, pp. 155-185.

Wisdom, Charles (1940), The Chorti indians of Guatemala, Chicago: Ed. Universidad de Chicago. 


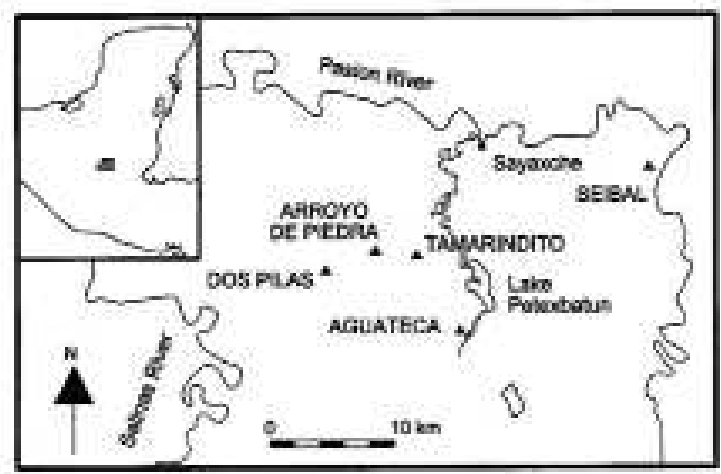

Figura 1

Mapa de la región Petexbatún, El Petén, Guatemala, que muestra la ubicación de Aguateca (adaptado de Inomata 1997: figura 1, cortesía del Proyecto Arqueológico Aguateca).

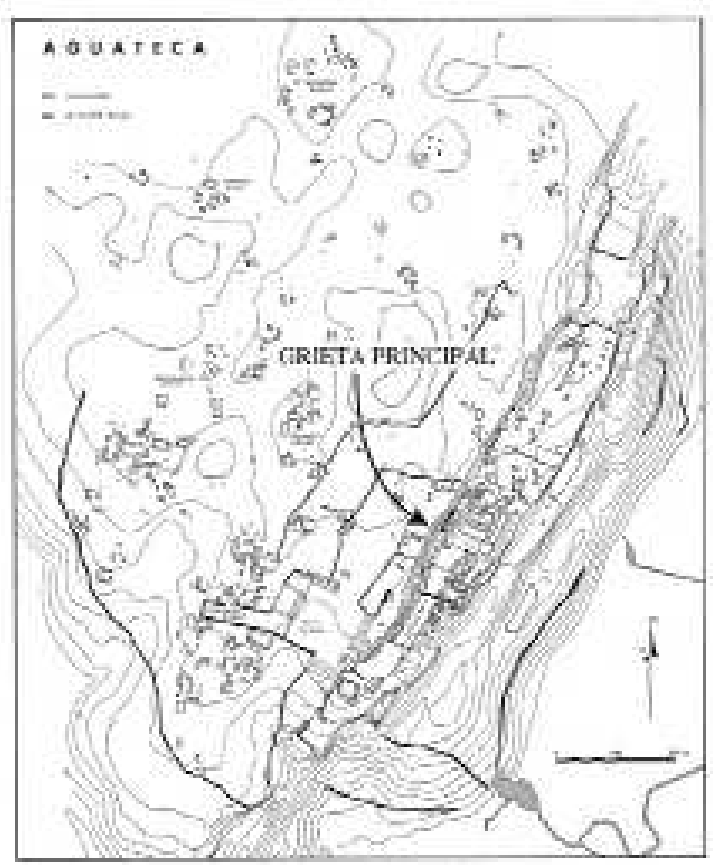

Figura 2

Mapa del asentamiento de Aguateca, que indica la ubicación de la Grieta Principal (adaptado de Inomata 1997: figura 3, cortesía del Proyecto Arqueológico Aguateca).

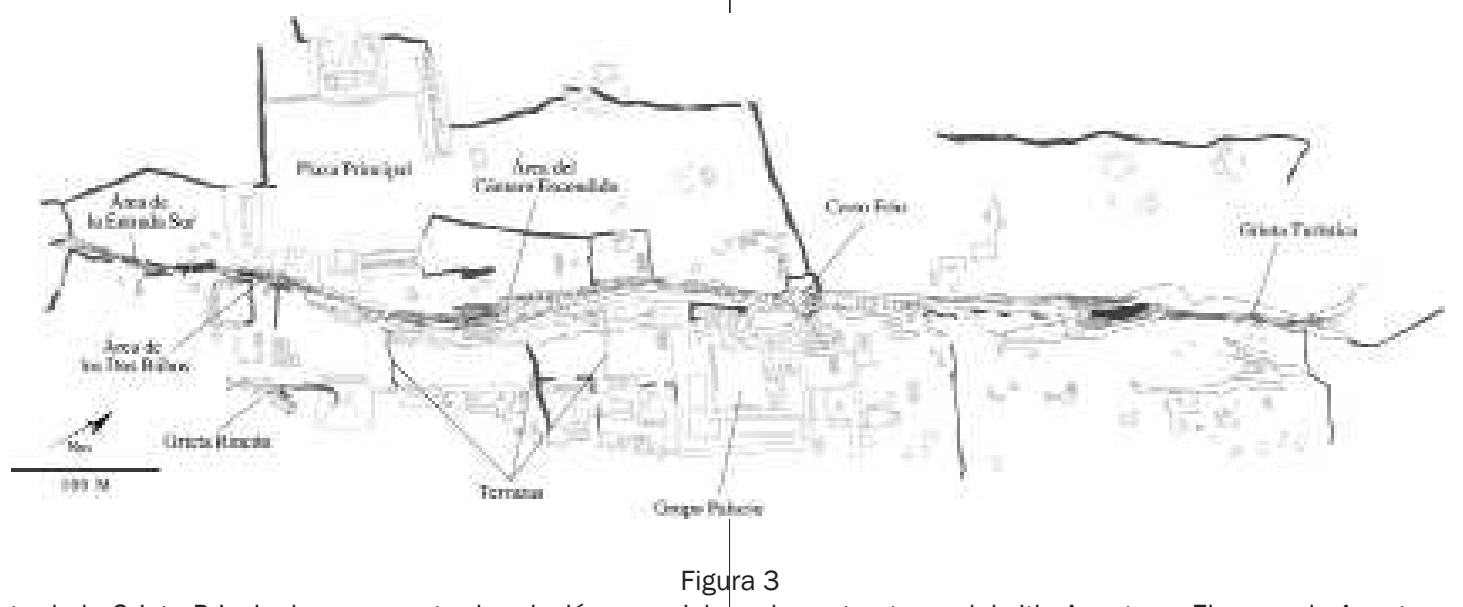

Planta de la Grieta Principal, que muestra la relación espacial con las estructuras del sitio Aguateca. El mapa de Aguateca que contiene las estructuras es cortesía del Proyecto Arqueológico Regional Petexbatún y el Proyecto Arqueológico Aguateca. El mapa de la grieta fue realizado por Bev Shade, Nick Johnson, Doug Weinberg y Philip Rykwalder, y dibujado por Bev Shade (adaptado de Ishihara 2007: figura D.2).

Revista LiminaR. Estudios sociales y humanísticos, año 7, vol. VII, núm. 1, junio de 2009, Tuxtla Gutiérrez, Chiapas, México. ISSN: 1665-8027 
MÚsica PARA LAS DIVINIDADES DE LA LLUUVIA. ReCONSTRUCCIÓN

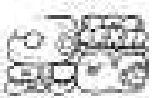

b.

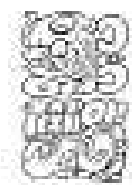

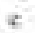

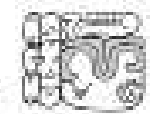

4

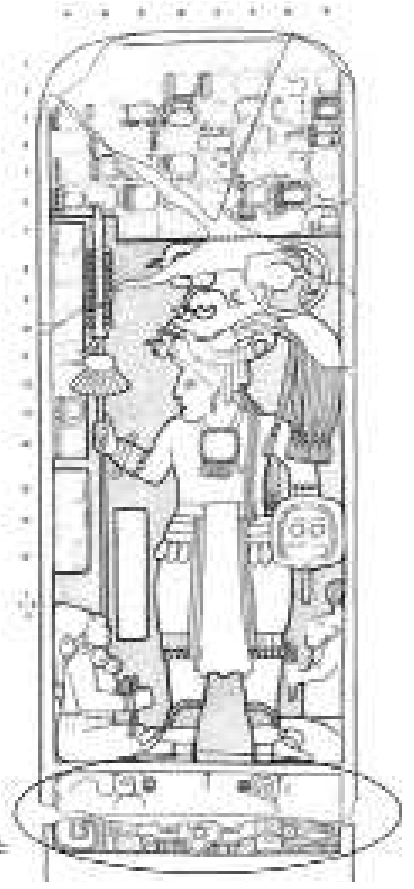

Figura 4

El glifo toponómico de Aguateca, leido K'inich Pa' Witz. Se puede observar el cerro (witz) partido el cual representa gráficamente la Grieta Principal en la cima de la escarpa. a. Aguateca Estela 2; b. Aguateca Estela 1; c. Aguateca Estela 7; d. Escalera Jeroglífica 2 de Dos Pilas, Este, Escalón 5; e. Aguateca Estela 6. (a-c son adaptado de Stuart y Houston 1994:10, fig.8; d de Fahsen 2003; e de Graham 1967:fig.15, Ponciano y Monroy 2005:fig.2.9).

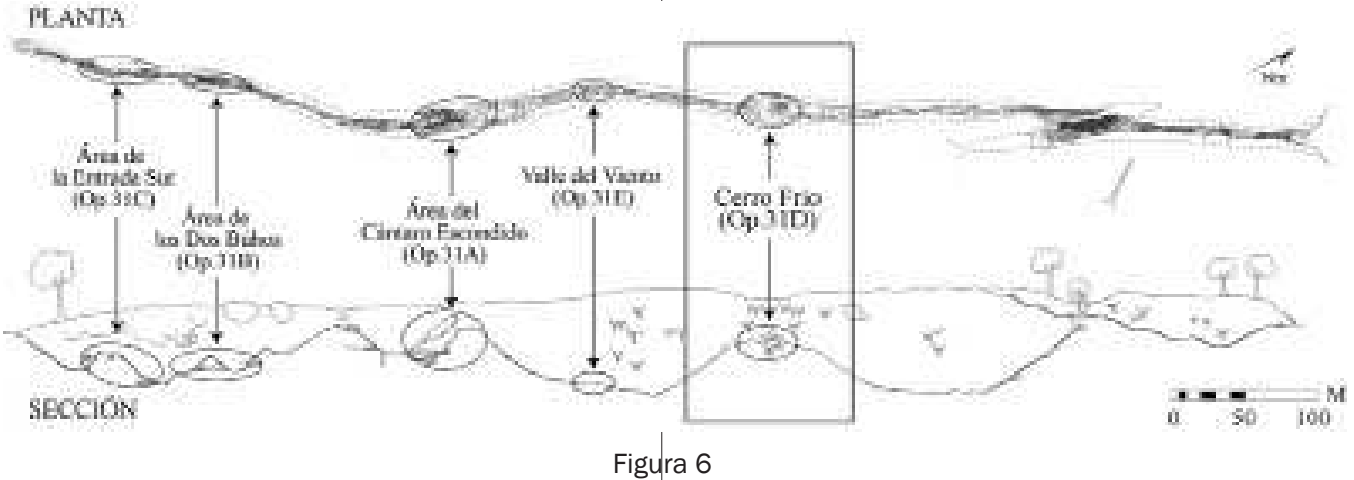

Planta y sección de la Grieta Principal. La línea de puntos en la planta representa el contorno de la grieta arriba en la superficie. E mapeo fue realizado por Bev Shade, Nick Johnson, Doug Weinberg y Philip Rykwalder en el junio de 2004; el mapa fue dibujado por Shade (adaptado de Ishihara 2007: figura D.1). 


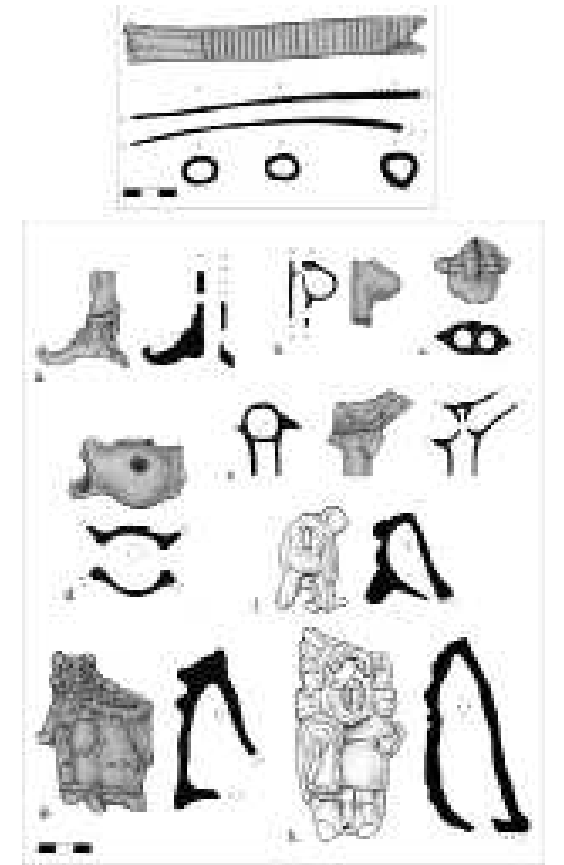

Figura 7

Instrumentos de música recolectados de la Unidad 1 de la Cámara 5 y Unidades 2 y 5 de la Cueva, Cerro Frío. Superior: Raspador del hueso (Unidad 5, Cueva); Inferior: a-c. Flautas con uno o dos cámaras resonantes, d-e. Instrumentos de viento con cámaras resonantes múltiples, f-h. Ocarinas con una cámara resonante (a-e. Unidad 5, Cueva; f-g. Unidad 1, Cámara 5; h. Unidad 2, Cueva). Dibujos por Alfredo Román. Escala en cm.

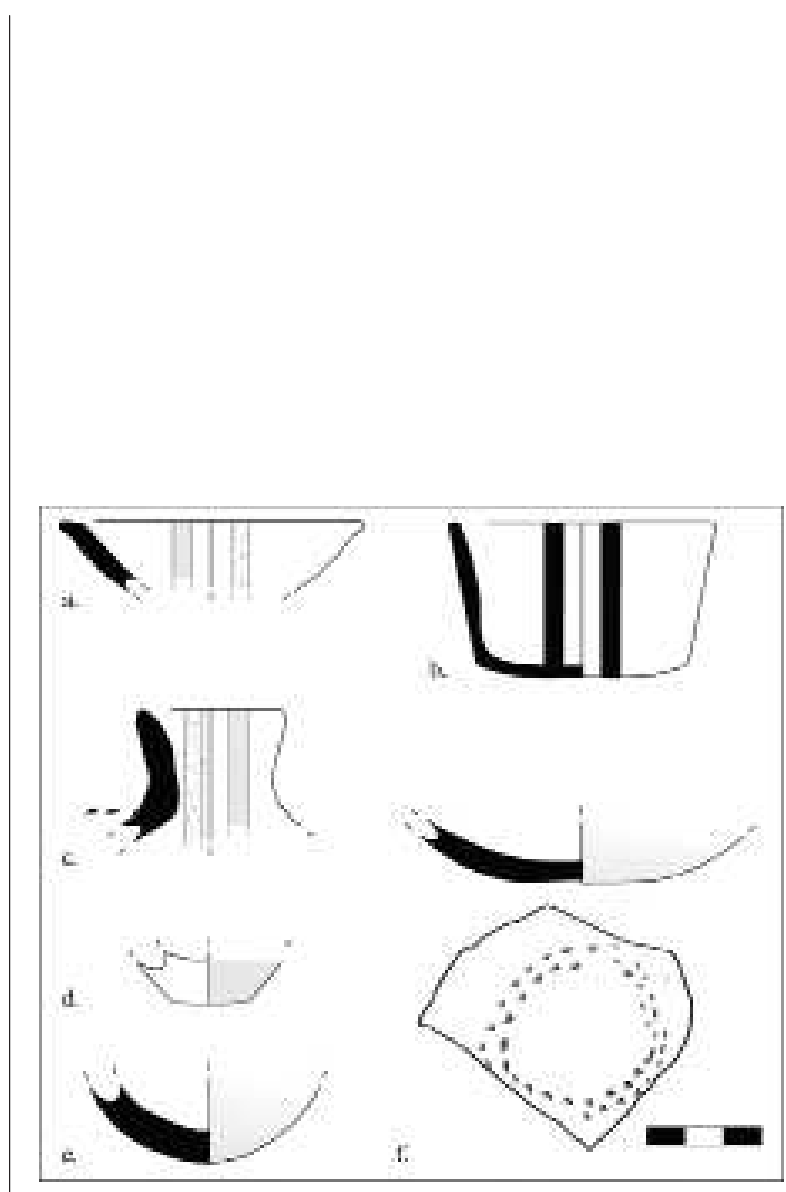

Figura 8

Vasijas miniaturas recolectadas de la Unidad 1 en la Cámara 5 del Cerro Frío. a. Cuenco, tipo Tinaja Rojo; b. Cuenco, tipo Infierno Negro; c-f. Tinajas, tipo Tinaja Rojo o Pantano Impreso. (a, d, e: Lote 4-1; c. Lote 3-1; b, f: Lote 6-1). Escala en cm. 
Música PaRa las DIVINIDADES DE LA LLUVIA. RECONSTRUCCIÓN

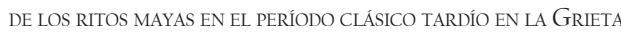

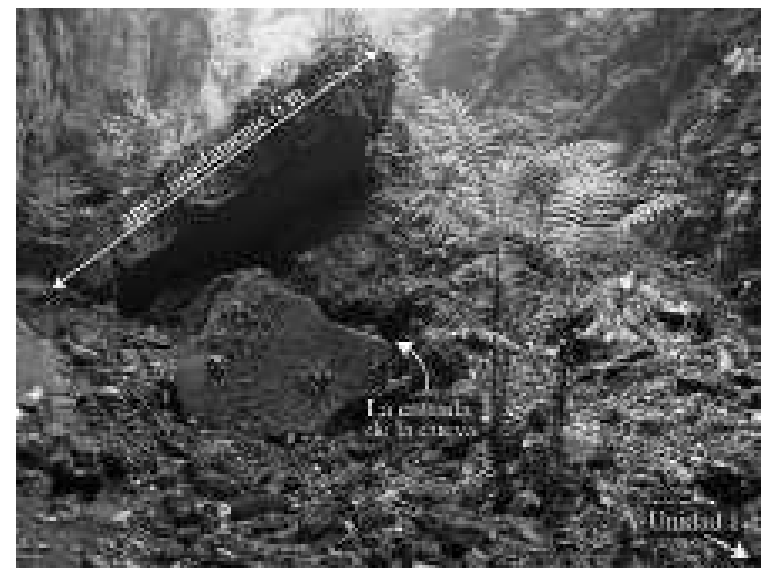

Foto 1

El Cerro Frío, viendo al norte. Se muestra la entrada de la cueva; y la Unidad 1 está ubicada afuera de la foto hacia la parte abajo y derecha (adaptado de Ishihara 2007: figura 3.10).

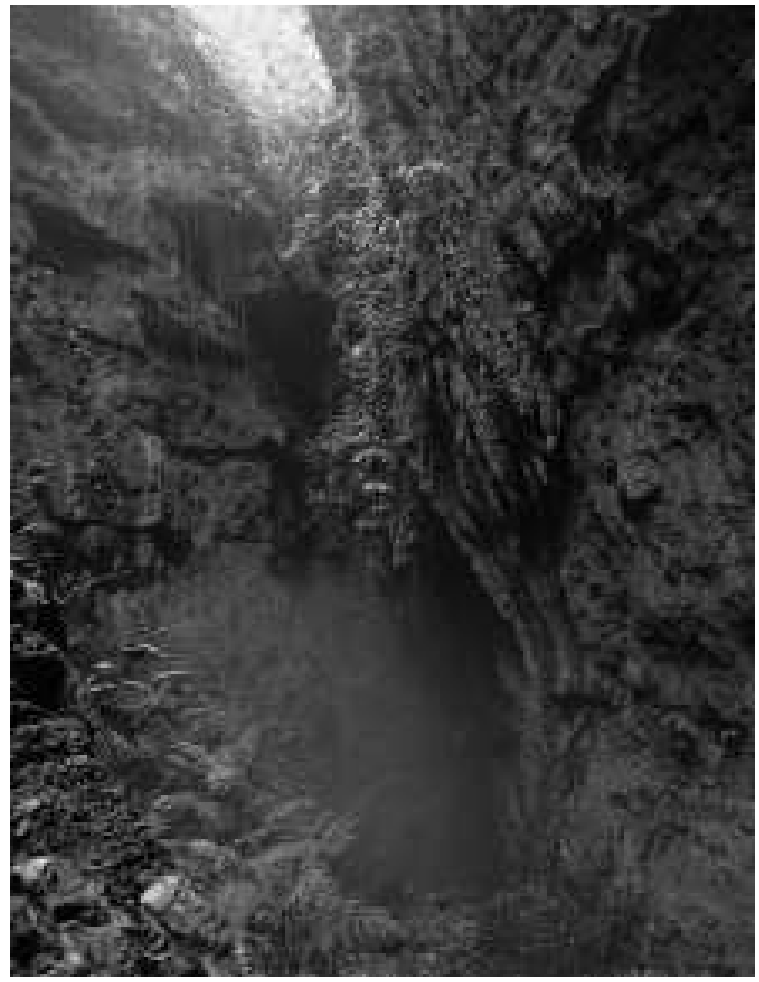

Foto 2

Nubes densas subiendo al Cerro Frío, desde el sur (adaptado de Ishihara 2007: figura 8.3). 
Tabla 1

Frecuencia de los instrumentos de música fragmentados, por área de investigación.

\begin{tabular}{|c|c|c|c|c|c|c|}
\hline & \multicolumn{3}{|c|}{ Tambor } & \multirow[t]{2}{*}{ Flauta } & \multirow[t]{2}{*}{ Ocarina } & \multirow[t]{2}{*}{ Raspador } \\
\hline & peso $(\mathrm{g})$ & borde & frec & & & \\
\hline Área del Cántaro Escondido (Op. 31A) & 155 & 1 & 7 & 0 & 0 & 1 \\
\hline $\begin{array}{l}\text { La pendiente entre las Cámaras Interior y Ex- } \\
\text { terior (Unidades } 2,5 \text { ) }\end{array}$ & 34 & 0 & 1 & 0 & 0 & 0 \\
\hline La Cámara Interior (U 1, 3, 4, 11, 12) & 77 & 1 & 5 & 0 & 0 & 1 \\
\hline La Cámara Exterior $(U$ 9, 10) & 0 & 0 & 0 & 0 & 0 & 0 \\
\hline $\begin{array}{l}\text { El altar-plataforma en la entrada a la Cámara } \\
\text { Interior }(\cup 6,13)\end{array}$ & 44 & 0 & 1 & 0 & 0 & 0 \\
\hline Área de los Dos Búhos (Op. 31B) & 1176 & 19 & 92 & 1 & 5 & 0 \\
\hline $\begin{array}{l}\text { La Cámara de los Dos Búhos, General (U 2, } \\
3,5,13)\end{array}$ & 0 & 0 & 0 & 0 & 0 & 0 \\
\hline Escalón 1 (U 8) & 0 & 0 & 0 & 0 & 0 & 0 \\
\hline Muro 2 (U 9) & 0 & 0 & 0 & 0 & 0 & 0 \\
\hline El Pasaje Rocoso (U 4) & 47 & 0 & 1 & 0 & 0 & 0 \\
\hline El Pasaje 1, general (U 1) & 9 & 0 & 1 & 0 & 0 & 0 \\
\hline El Pasaje 1, la parte norte $(\mathrm{U} 6,10)$ & 429 & 7 & 38 & 0 & 0 & 0 \\
\hline $\begin{array}{l}\text { El Pasaje 1, la parte central de las actividades } \\
(\cup 7,11)\end{array}$ & 0 & 0 & 0 & 0 & 1 & 0 \\
\hline El Pasaje 1, la parte sur (U 12) & 161 & 1 & 13 & 0 & 2 & 0 \\
\hline Sur del Pasaje 1 (U 14) & 530 & 11 & 39 & 1 & 2 & 0 \\
\hline La Cueva bajo el puente (U 15) & 0 & 0 & 0 & 0 & 0 & 0 \\
\hline Área de la Entrada Sur (Op. 31C) & 301 & 4 & 15 & 0 & 3 & 0 \\
\hline El Pasaje Entrada (U 1, 11) & 0 & 0 & 0 & 0 & 0 & 0 \\
\hline El Túnel bajo el Pozo (U 2) & 0 & 0 & 0 & 0 & 0 & 0 \\
\hline La Cámara Superior (U 3, 6, 8, 9, 10) & 301 & 4 & 15 & 0 & 3 & 0 \\
\hline El Pasaje Nasal (U 4) & 0 & 0 & 0 & 0 & 0 & 0 \\
\hline El Pasaje $8(\cup 5,7)$ & 0 & 0 & 0 & 0 & 0 & 0 \\
\hline Cerro Frío (Op. 31D) & 351 & 7 & 22 & 8 & 18 & 1 \\
\hline La Cámara 5 (U 1) & 117 & 4 & 7 & 0 & 9 & $\mathbf{0}$ \\
\hline Dentro de la cueva $(U \mathrm{U}, \mathbf{5})$ & 107 & 3 & 5 & 5 & 8 & 1 \\
\hline La entrada de la cueva (U 6) & 0 & $\mathbf{0}$ & $\mathbf{0}$ & 3 & 0 & $\mathbf{0}$ \\
\hline Al oeste de la cueva $(\mathrm{U} 3, \mathbf{4})$ & 109 & o & 9 & 0 & 0 & $\mathbf{0}$ \\
\hline El cerrito con posibles escalones $(U \mathrm{U}, 9)$ & 18 & 0 & 1 & 0 & 1 & $\overline{0}$ \\
\hline AI noroeste de la cueva (U 7) & o & $\mathbf{0}$ & $\mathbf{0}$ & 0 & 0 & $\mathbf{0}$ \\
\hline Valle del Viento (Op. 31E) & 57 & 0 & 4 & 0 & 1 & 0 \\
\hline TOTAL & 2040 & 31 & 140 & 9 & 27 & 2 \\
\hline
\end{tabular}

